\title{
MUDANÇAS PERIÓDICAS DOS INGREDIENTES ALIMENTARES ASSOCIADAS ÀS DIFERENTES FORMAS DE RAÇÃO NO DESEMPENHO DE FRANGOS DE CORTE
}

\author{
G.J.M., MILTENBURG; R.D.M. SILVA; I.U. PACKER \\ Departamento de Zootecnia - ESALQ/USP, C.P. 9 - CEP: 13418-900 - Piracicaba,SP
}

\begin{abstract}
RESUMO: Efeitos da forma de ração (triturada e farelada), sexos e mudanças semanais na composição centesimal das raçōes no peso corporal, ganho de peso e conversão alimentar de frangos de corte no periodo de 1 até 49 dias de idade, foram testados através de delineamento fatorial $2 \times 2 \times 2, \operatorname{com} 3$ repetições de 50 aves cada. A ração basal foi formulada para conter milho moído, farelo de soja, fosfato bicálcico, calcáreo, gordura animal, sal e suplemento de vitaminas, minerais e aditivos. As mudanças na composição foram feitas pela redução do nível de farelo de soja e calcáreo, retirada da gordura animal e introdução de protenose, farelo de algodão e farinha de carne e ossos. As rações foram formuladas para serem isocalóricas e isoprotécas. Os resultados indicaram que a forma triturada da ração contribuiu para melhorar o desempenho de frangos de corte. $O$ ganho de peso e o peso corporal em diversos periodos experimentais foram superiores quando as raçōes sofreram mudanças bruscas na composição alimentar, porém, a conversão alimentar piorou. Foram observadas interacōes duplas e triplas significativas $(P<0,05)$, porém, como a análise de variância não indicou diferenças significativas dessas variáveis isoladas dentro dos periodos considerados, não foi possível concluir-se sobre 0 efeito de uma variável sobre as demais.
\end{abstract}

Descritores: formas de ração, frangos de corte.

\section{PERIODICAL. CHANGES OF THE FEEDSTUFFS ASSOCIATED TO DIFFERENT FORMS OF RATION ON BROILER PERFORMANCE.}

\begin{abstract}
ARSTRACT: The effects of forms of ration (crumbles and mash), sexes and weekly changes of the percent composition of the rations were tested on broiler performance. Basal ration was formulated to contain ground corn, soybean oil meal, dicalcium phosphate, limestone, animal fat, salt and vitamin, mineral and additive premix. Changes of the composition were made to reduce soybean oil meal and limestone levels, removal of animal fat and incorporation of com gluten meal, cottonsed meal and meat and bone meals. Rations were isocaloric and isoproteic. The results showed that the crumble form of the ration contributed to improve broiler performance. Body weight and body weight gain in several experimental periods were higher when sudden changes in feed composition occurred. Feed conversion was poorer as feed composition changed. There were significant $(P<0,05)$ double and triple interactions, however as analyses of variance did not show significant differences of the single variables within the periods, it was not possible to take conclusions on the effect of one variable with respect to others.
\end{abstract}

Key Words: forms of ration, broilers.

\section{INTRODUÇÃO}

Os objetivos da utilização da programação linear na formulação de rações são os de obter misturas balanceadas que possibilitem atingir o desempenho animal máximo ao menor custo possivel. O nutricionista animal moderno não pode prescindir dessa eficiente ferramenta de trabalho para a sua atividade profissional. Entretanto, em algumas ocasiões a composição de uma mistura balanceada pode sofrer alterações radicais em consequência das oscilações de preços ou da indisponibilidade de alguns ingredientes alimentares as quais resultam em mudanças bruscas que podem eventualmente modificar a cor, textura e palatabilidade das rações podendo mesmo afetar o consumo alimentar e prejudicar o desempenho animal.

o presente experimento teve por objetivo testar o efeito das mudanças bruscas dos alimentos componentes das rações no desempenho de frangos de corte. Foram utilizadas rações fareladas e trituradas para se verificar o efeito da forma da ração nas mudanças dos ingredientes.

Revisão da literatura

AUCKLAND \& FULTON (1971) observaram que a taxa de crescimento foi maior 
com o uso de ração triturada comparada com a farelada no desempenho de frangos de corle. AUCKLAND \& FULTON (1972) concluiram que frangos de corte alimentados com ração triturada cresceram mais rapidamente que as aves alimentadas com ração farelada. A mortalidade embora sem diferença significativa foi maior entre as aves alimentadas com a forma triturada.

As aves alimentadas com ração na forma farelada ingeriram $7 \%$ mais alimento que as alimentadas com ração triturada. Estudando o efeito da textura do alimento sobre o desempenho de frangos de corte, RUNNELS et al. (1976) observaram que as aves alimentadas com ração triturada foram mais pesadas ( $\mathrm{P}<0,001$ ) e consumiram menos alimento por quilo ganho de peso $(P<0,01)$. Esta observação confirma a prática comercial de alimentar os frangos até a quarta semana de idade com ração na forma triturada.

Da quarta semana a oitava semana de idade, as formas granulada, granulada peneirada, triturada, metade granulada e metade triturada quando comparadas com a forma farelada, apresentaram aves com médias de peso corporal maiores $(\mathrm{P}<0,01)$.

SIPE \& POLK (1939) foram os primeiros pesquisadores a realizarem experimento com poedeiras à respeito das mudanças bruscas da composição alimentar na produção de ovos. Esses pesquisadores observaram que a produção não foi afetada, como também não houve muda das penas durante o primeiro mês após as mudanças. A mudança brusca da composição alimentar prejudicou a produção de ovos devido a redução do consumo alimentar e ocorrência de muda das penas.

A alteração da cor da ração não teve muita influência na produção de ovos (O'NEIL, 1946). LEESON et al. (1979) concluiram que apesar da utilização da programação linear resultar em alteracões radicais na composição alimentar de rações de postura de custo mínimo, a produção de ovos não foi afetada.

SILVA (1981) concluiu que as alterações bruscas efetuadas a cada 14 dias nos ingredientes alimentares das rações experimentais afetaram negativamente $o$ peso corporal de frangos de corte machos e fềmeas no período até 42 dias de idade, bem como, o ganho médio de peso do lote misto no período de 14 a 42 dias de idade.

\section{MATERIAL E MÉTODOS}

Foram testados os efeitos da forma da ração (triturada e farelada), sexo (macho e fêmea) e mudança semanal ou não na composição centesimal das rações sobre o peso corporal, ganho de peso e conversão alimentar, no período de 1 até 49 dias de idade, através de um delineamento fatorial $2 \times 2 \times 2$. Cada combinação desses fatores foi fornecida a 3 repetições de 50 aves cada, de modo inteiramente ao acaso. As aves, da linhagem Hubbard, foram pesadas semanalmante.

A ração basal foi formulada para conter milho moído, farelo de soja tostada, fosfato bicálcico, calcáreo calcítico, gordura animal, sal moído e suplemento de vitaminas, minerais e aditivos. As mudanças na composição foram feitas pela redução do farelo de soja e calcáreo, retirada da gordura animal e introdução de protenose, farelo de algodão e farinha de carne e ossos.

As rações experimentais eram isocalóricas e isoprotéicas. Os dados foram submetidos à análise da variância para o modelo fatorial, sendo os efeitos principais e as interações testadas pelo teste " $F$ " com nível de significância de $5 \%$.

\section{RESULTADOS E DISCUSSÃO}

As médias dos pesos corporais, ganhos de peso e conversões alimentares médias nas várias idades por formas de ração, mudanças e sexos, são mostradas na TABELA 1. A mortalidade observada nos períodos de 0 a 28 e de 29 a 49 dias de idade é apresentada na mesma TABELA.

$A$ análise dos dados indicou que frangos de corte alimentados com rações trituradas apresentaram médias de pesos corporais aos 7, 14, 35,42 e 49 dias de idade que foram superiores $(P$ $<0,05$ ) as médias das aves alimentadas com rações fareladas. As médias dos pesos corporais aos 21 e 28 dias de idade das aves que receberam rações trituradas foram também superiores as médias das aves que receberam rações fareladas, porém, as diferenças encontradas não foram significativas no nível testado.

Esses resultados confirmam a maioria dos trabalhos sobre melhoria do desempenho de frangos de corte alimentados com rações granuladas ou trituradas quando comparada com a forma farelada (AUCKLAND \& FULTON, 1971; AUCKLAND \& FULTON, 1972 e RUNNELS et al., 1976). 
TABELA 1 - Médias dos pesos corporais semanais, ganhos de peso semanais, conversão alimentar semanais cumulativa e mortalidade de acordo com a forma da ração, mudanças e sexo.

\begin{tabular}{|c|c|c|c|c|c|c|}
\hline f́tem & $\begin{array}{c}\text { Forma } \\
\text { Farelada }\end{array}$ & $\begin{array}{l}\text { Forma } \\
\text { Triturada }\end{array}$ & $\begin{array}{c}\text { Mudança } \\
\text { Sem }\end{array}$ & $\begin{array}{c}\text { Mudança } \\
\text { Com }\end{array}$ & $\begin{array}{c}\text { Sexo } \\
\text { Machos }\end{array}$ & $\begin{array}{c}\text { Sexo } \\
\text { Fêmeas }\end{array}$ \\
\hline \multicolumn{7}{|c|}{ Peso corporal (gramas) } \\
\hline 7 dias a,c & 120 & 124 & 123 & 122 & 124 & 120 \\
\hline 14 dias a,c & 253 & 262 & 255 & 259 & 264 & 251 \\
\hline 21 dias c & 512 & 515 & 507 & 520 & 537 & 490 \\
\hline 28 dias $b, c$ & 823 & 835 & 819 & 838 & 879 & 779 \\
\hline 35 dias $a, b, c$ & 1125 & 1150 & 1126 & 1149 & 1225 & 1050 \\
\hline 42 dias a,c & 1531 & 1556 & 1533 & 1554 & 1678 & 1409 \\
\hline 49 dias a,c & 1916 & 1996 & 1933 & 1952 & 2128 & 1757 \\
\hline \multicolumn{7}{|c|}{ Ganho de peso (kg) } \\
\hline $0-14 \mathrm{a}, \mathrm{c}$ & 216 & 225 & 218 & 164 & 226 & 214 \\
\hline $0-21 c$ & 475 & 478 & 471 & 483 & 500 & 454 \\
\hline $0,28 \mathrm{~b}, \mathrm{c}$ & 786 & 798 & 783 & 801 & 841 & 743 \\
\hline $0-35$ & 1088 & 1113 & 1089 & 1112 & 1188 & 1013 \\
\hline $0-42 a, c$ & 1494 & 1519 & 1496 & 1517 & 1641 & 1372 \\
\hline $0-49$ a,c & 1879 & 1932 & 1896 & 1915 & 2091 & 1720 \\
\hline \multicolumn{7}{|c|}{ Conv. Alimentar $(\mathrm{kg} / \mathrm{kg})$} \\
\hline $0-14$ & 1,68 & 1,62 & 1,64 & 1,65 & 1,68 & 1,62 \\
\hline $0-21$ & 1,59 & 1,60 & 1,58 & 1,61 & 1,58 & 1,61 \\
\hline $0-28$ & 1,67 & 1,68 & 1,65 & 1,67 & 1,64 & 1,68 \\
\hline $0-35$ a,c & 1,85 & 1,81 & 1,82 & 1,84 & 1,80 & 1,87 \\
\hline $0-42 a, c$ & 1,89 & 1,86 & 1,87 & 1,89 & 1,85 & 1,91 \\
\hline $0-49$ & 1,99 & 1,94 & 1,95 & 1,98 & 1,92 & 2,00 \\
\hline \multicolumn{7}{|l|}{ Mort. (\%) } \\
\hline $0-28$ dias & 1,6 & 1,0 & 0,9 & 1,7 & 1,2 & 1,4 \\
\hline 29-42 dias & 0,4 & 0,0 & 0,5 & 0,0 & 0,4 & 0,0 \\
\hline
\end{tabular}

Obs.: $\underline{a}$ indica efeito significativo da forma da ração, $\underline{b}$ indica efeito significativo de mudança de ração $e$ $\underline{\mathbf{c}}$ indica efeito significativo do sexo. O nível de significância foi de 0,05 , conforme o teste "F". 
Os frangos de corte alimentados com rações que sofreram mudanças na composição alimentar a intervalos semanais apresentaram médias de pesos corporais aos 28 e 35 dias de idade que foram superiores $(P<0,05)$ as médias das aves alimentadas com rações que não sofreram alterações nas suas composições alimentares. As médias dos pesos corporais aos $14,21,42$ e 49 dias de idade das aves que receberam rações que sofreram mudanças nas composições alimentares foram superiores as médias das aves alimentadas com rações cujas composições alimentares não foram alteradas a intervalos semanais, porém, as diferenças não foram significativas. Os trabalhos sobre mudanças na composição alimentar em aves poedeiras indicam que as aves adultas em postura não foram afetadas pela mudança de ingredientes da ração (SIPE \& POLK, 1939; O,NEIL, 1946; LEESON et al., 1979). Os resultados deste trabalho porém, não são concordantes com os obtidos por SILVA (1981) em frangos de corte.

Os machos passaram a apresentar médias de pesos corporais superiores $(P<0,05)$ a partir de 7 dias de idade. Não foram observadas interações entre os tratamentos nas médias dos pesos corporais. O desempenho dos frangos de corte auferido pelo ganho de peso apresentou resultados que foram semelhantes aos obervados para o peso corporal. A ração na forma triturada mostrou tendência em melhorar a conversão alimentar dos frangos de corte nos períodos finais de criação. Ao contrário do observado com as médias de peso corporal e ganho de peso, a mudança dos ingredientes alimentares piorou as médias das conversões alimentares. Entretanto, esse efeito só foi observado no último período experimental de criação.

Houve interação significativa entre forma de ração e mudanças de ingredientes no ganho de peso das aves somente no período de 7 a 21 dias de idade. Porém, o desdobramento não indicou nenhuma diferença significativa entre formas dentro das classes de mudanças.

Foi observada interação $(P<0,05)$ nos períodos de 0 a 21 e 0 a 35 dias de idade entre forma de ração, mudança dos ingredientes alimentares e sexos, indicando que os sexos apresentaram diferenças nas conversões alimentares conforme a forma e mudanças dos ingredientes das rações experimentais. Porém, ,como não foram observadas diferenças significativas para uma ou mais variáveis nos períodos citados, não foi possível concluir-se sobre o efeito de uma variável sobre as demais.

\section{CONCLUSÕES}

- A forma triturada da ração contribuiu para melhorar o desempenho de frangos de corte.

- O ganho de peso e o peso corporal em diversos períodos experimentais foram superiores quando as rações sofreram mudanças bruscas na composição alimentar.

- As rações que sofreram alterações bruscas na composição alimentar pioraram a conversão alimentar de frangos de corte.

\section{REFERÊNCIAS BIBLIOGRÁFICAS}

AUCKLAND, J.N.; FULTON, R.B. Effect of energy concentration on the response to pelleting in broiler diets. World's Poultry Science Journal, London, v.27, n.2, p.162, 1971 .

AUCKLAND, J.N.; FULTON, R.B. The effects of dietary nutrient concentration, crumbles versus mash and age of dam on the growth of broiler chicks. Poultry Science, Champaign, v.51, p.1968-1975, 1972.

LEESON, S.; SUMMERS, J.D.; SCHEFER, K. Performance of layers confronted with monthly changes in diet composition. Poultry Science, Menasha, v.58, v.5, p.1330-1336, 1979.

O'NEIL, J.B. The effect of sudden changes of feed upon production. Poultry Science, Menasha, v.25, n.1, p.83-85, 1946.

RUNNELS, T.D.; MALONNE, G.W.; KLOPP, S. The influence of feed texture on broiler performance. Poultry Science, Menasha, v.55, n.5, p.1958-1961, 1976.

SILVA, R.D.M. Métodos de formulação de raçōes em dois níveis de energia e proteína associados às mudanças periódicas dos ingredientes alimentares $e$ seus efeitos no desempenho de frangos de corte. Piracicaba, 1981. 199 p. Tese (Livre-docência) Escola Superior de Agricultura "Luiz de Queiroz", Universidade de São Paulo.

SIPE, G.R.; POLK, H.D. The response of laying hens to sudden feed changes. Poultry Science, Menasha, v.18, n.5, p.394-398, 1939.

Enviado para publicação em 06.05 .92

Aceito para publicação em 30.07 .93 